\title{
ASO Author Reflections: Improving Management of Upper Limb Complications after Breast Cancer Treatments
}

\author{
Nur Amalina Che Bakri, MBChB, BMedSc (Hons), MPhil ${ }^{1,2}$ (D) , Richard M. Kwasnicki, PhD, MRCS ${ }^{1,2}$, \\ Kieran Dhillon, BSc ${ }^{1}$, Naairah Khan, MB, BCh, BAO, BSc (Hons) ${ }^{1}$, Omar Ghandour, MBChB, BSc (Hons) ${ }^{1}$, \\ Alexander Cairns, MBBS $^{2}$, Ara Darzi, FRCS, FRS ${ }^{1,2}$, and Daniel R. Leff, PhD, MS (Hons), FRCS ${ }^{1,2}$ \\ ${ }^{1}$ Department of Surgery and Cancer, Imperial College London, London, UK; ${ }^{2}$ Academic Surgical Unit, Imperial College \\ Healthcare NHS Trust, St. Mary's Hospital, London, UK
}

\section{PAST}

The impact of treatments on breast cancer survivors should be objectively reported given rising incidence and improvements in survival, meaning more women are living with the impact of treatment. ${ }^{1}$ Historically, without a focus on survivorship, monitoring of upper limb dysfunction (ULD) has been largely piecemeal and subjective. ${ }^{2}$ Validated approaches for measuring ULD based on introspective reporting are prone to bias. For example, the DASH (Disability of Shoulder, Arm and Hand) questionnaire reflects a person's (possibly skewed) perception of their own functionality. Current objective indicators, such as arm volume (lymphedema), on the other hand, do not represent functional morbidity and provide poor comparison between patients. ${ }^{3}$

\section{PRESENT}

Technological advances have led to the development of non-invasive and non-obtrusive wearable activity monitors (WAMs) for tracking physical activity. In oncology trials, WAMs are being used to study the association between physical activity and outcomes. ${ }^{4}$ Increased physical activity has been linked to better cancer patient outcomes with improvement in quality of life, complication rates and

(C) Crown 2021

First Received: 30 June 2021

Accepted: 1 July 2021

Published Online: 24 August 2021

Nur Amalina Che Bakri, MBChB, BMedSc (Hons), MPhil e-mail: nchebakr@ic.ac.uk hospital length of stay. ${ }^{3,5}$ We recently assessed the feasibility of using WAMs to objectively monitor upper limb functional recovery after different types of breast cancer treatments. ${ }^{6}$ This study investigated upper limb activities in breast cancer cohort. The findings demonstrated a reduction in arm function on the operated side, followed by a slow recovery that does not return to baseline even at 2 weeks after surgery. During the 2-week post-operative period, the unoperated side was more active than the operated side. Since the pattern of post-operative physical morbidity is as predicted, i.e. a post-operative drop followed by a progressive recovery to baseline, construct validity has been established. Physical activity data measured by WAMs seem to be able to differentiate between surgical procedures. ${ }^{6}$ The concurrent validity of WAMs was demonstrated by the moderate negative correlation between activity levels and functional (DASH) surveys. This demonstrates the utility of the WAMs as an objective tool for assessing functional morbidity.

\section{FUTURE}

This research will be a starting point for future research into how WAMs may help with feedback-enabled prehabilitation and rehabilitation. A screening tool to identify individuals at risk of developing upper limb complications or requiring additional support can be developed in conjunction with engineers and physiotherapists by measuring and characterizing upper limb morbidity. Patients' upper limb activities can be tracked as part of an enhanced recovery care plan to encourage them to take charge of their own care, led by their own individualized activity goals. This is an important step towards improving outcomes and quality of life for breast cancer survivors. 


\section{DISCLOSURE}

No conflicts of interest to declare.

FUNDING National Institute for Health Research (NIHR) Imperial Biomedical Research Centre (BRC). Award number: WSSS_P69945.

OPEN ACCESS This article is licensed under a Creative Commons Attribution 4.0 International License, which permits use, sharing, adaptation, distribution and reproduction in any medium or format, as long as you give appropriate credit to the original author(s) and the source, provide a link to the Creative Commons licence, and indicate if changes were made. The images or other third party material in this article are included in the article's Creative Commons licence, unless indicated otherwise in a credit line to the material. If material is not included in the article's Creative Commons licence and your intended use is not permitted by statutory regulation or exceeds the permitted use, you will need to obtain permission directly from the copyright holder. To view a copy of this licence, visit http://creativecommons. org/licenses/by/4.0/.

\section{REFERENCES}

1. Cancer Research UK. Breast Cancer Statistics. Cancer Research UK website. 2021. https://www.cancerresearchuk.org/health-profe ssional/cancer-statistics/statistics-by-cancer-type/breast-cancer\#he ading-Three. Accessed 17 Apr 2021.

2. Hidding JT, Beurskens $\mathrm{CH}$, van der Wees PJ, van Laarhoven HW. Nijhuis-van der Sanden MW. Treatment related impairments in arm and shoulder in patients with breast cancer: a systematic review. PLoS One. 2014;9(5):e96748.

3. Schrack JA, Gresham G, Wanigatunga AA. Understanding physical activity in cancer patients and survivors: new methodology, new challenges, and new opportunities. Cold Spring Harb Mol Case Stud. 2017;3(4).

4. Gresham G, Schrack J, Gresham LM, et al. Wearable activity monitors in oncology trials: current use of an emerging technology. Contemp Clin Trials. 2018;64:13-21.

5. Luther A, Gabriel J, Watson RP, Francis NK. The impact of total body prehabilitation on post-operative outcomes after major abdominal surgery: a systematic review. World J Surg. 2018;42(9):2781-91.

6. Che Bakri NA, Kwasnicki RM, Dhillon K, et al. Objective assessment of postoperative morbidity after breast cancer treatments with wearable activity monitors: the "BRACELET" Study [published online ahead of print, 2021 Jul 26]. Ann Surg Oncol. 2021;1-13. https://doi.org/10.1245/s10434-021-10458-4.

Publisher's Note Springer Nature remains neutral with regard to jurisdictional claims in published maps and institutional affiliations. 